\title{
Co-Relation of Risk Factors for Surgical Site Infection in Patients Undergoing Surgery For Carcinoma of Breast
}

\author{
Vipul Goel ${ }^{1}$, N. K. Singh ${ }^{2 *}$
}

1Junior Resident, Department of General Surgery, Teerthanker Mahaveer Medical College \& Research Centre, Moradabad, Uttar Pradesh, India.

Email- vipulgoel041@gmail.com, Orcid ID: 0000-0001-6663-4928

2Professor \& Head, Department of General Surgery, Teerthanker Mahaveer Medical College \& Research Centre, Moradabad, Uttar Pradesh, India.

Email- dr.naveen.s@gmail.com, Orcid ID: 0000-0001-7156-9817

${ }^{*}$ Corresponding author

Received: 05 December 2021

Revised: 06 January 2022

Accepted: 18 January 2022

Published: 18 February 2022

\begin{abstract}
Background: Breast malignancy is one of the highest ranked malignancy occurring among Indian females, overall incidence being 25 per 1, 00,000 females varying across different states. Breast cancer surgeries are one of the commonest surgeries being conducted which is considered to be a clean procedure pretending to be at lower risk of complications. However it is has been observed that patient develops surgical site infection at an increased rate approximately $19 \%$ which leads to poor quality of life, increased hospital stay and delay in commencement of adjuvant therapies. The aim is to Co-relate risk factors for surgical site infection in patients undergoing surgery for carcinoma of breast. The objective of this study was to observe the relation of surgical site infection and its associated risk factors in the patient undergoing surgery for carcinoma breast. Material \& Methods: We analyzed 50 patients diagnosed with carcinoma breast and operated for the same in Teerthanker Mahaveer Medical College \& Research Centre, Moradabad, Uttar Pradesh. Patients were divided into two groups, Group A who develop surgical site infection and Group B who don't develop surgical site infection. All the predisposing factors including age, BMI, Addiction, co morbidity, Neo-adjuvant therapy, preoperative total leucocyte count were recorded. An observation was done with above mentioned risk factors and correlated with development of surgical site infection. Results: In our study we found that the risk factors associated with surgical site infection post breast cancer surgeries were age, BMI, co morbidity, Addiction and Neo-adjuvant therapy. Conclusions: Patients of Age more than 50years or who underwent Mastectomy or having associated comorbidity with co-relation to Smoking \& BMI more than 30, with Increased TLC count or who have received Neo-adjuvant chemotherapy are associated with increased risk of SSI following breast surgery which has led to increased hospital stay. There are many other studies who also concluded the relation of above factors with development of SSI post breast surgery, however further research is needed to elucidate the effect of prior manipulation and radiation therapy in development of SSI.
\end{abstract}

Keywords:- Breast Cancer,SSI,risk factors, BMI, Diabetes Mellitus

\section{INTRODUCTION}

Breast malignancy is one of the highest ranked malignancy occurring among Indian females, with overall incidence being 25.8 per 1,00,000 females varying across different states.[1] 
Annals of International Medical and Dental Research

E-ISSN: 2395-2822 | P-ISSN: 2395-2814

Vol-8, Issue-2 | March-April 2022

DOI: 10.53339/aimdr.2022.8.2.31

Page no- 245-251 | Section- Research Article (General Surgery)

Breast cancer treatment involves a multidisciplinary team which decides on various aspects of treatment protocol which includes surgery, radiation therapy and chemotherapy. Surgery is the major component of treatment for breast cancer patients which involves removal of tumor and different breast reconstructive surgeries which are done to maximize esthetic results. [2]

Despite of being such a common malignancy, it is being observed that wound infection comprises a major percentage of post-operative complications post breast surgery. [3]

Breast surgeries are being considered as a clean procedure, which pretends to be at lowest risk of complications (expected surgical site infection rate $3.4 \%$ ), with no exposure to any other body cavity like alimentary, respiratory, or Genito-urinary tracts. [4] However, this percentage is not obtained practically, with infection rates being reported up to $19 \%$, indicating that such surgeries be counted as clean-contaminated. $[5,6,7,8]$ There are many advances in treatment protocol and research work done in this area which has led to reduction in rates of infection but has not been fully successful.[9] Indeed breast cancer is now considered as a key variable associated with infection at wound site.

The SSI rate of non - cancer breast surgeries are lower when compared to similar surgeries done for cancer patients.

There has been trials to estimate the cost of such infection post breast surgery. However, it has been unsuccessful as the economic burden these infection costs are majorly post discharge and cost in terms of recurrent hospital visits and loss of quality of life cannot be quantified. $[10,11]$

SSI are associated with poor quality of life, increased hospital stays, poor cosmetic result and delay in commencement of adjuvant therapies. $[12,13,14]$

Various factors have been considered in patients of breast cancer which have been identified as the reason for high incidence of infection rate and this study has been designed to study those factors to gain a better understanding so that preventive strategies can be instituted in high-risk patients. $[15,16,17,18,19]$

Prevention of wound infection will not only decrease the overall mortality but also will decrease the overall economic burden on society \& health sector, thus enhancing the quality of patient's life with breast cancer.

\section{MATERIAL AND METHODS}

The study was conducted in department of General Surgery at Terthanker Mahaveer Medical College \& Resarch Centre, Moradabd, Uttar Pradesh, India. After obtaining Institutional Review bord Appoval, a retrospective study of medical files of patients with breast cancer operated between September 2019 to August 2021 was carried out. A total of 50 patients were taken into study.

\section{Participants}

Women aged between 18 - 80 years having histological diagnosis of carcinoma breast, clinically staged from stage 1 to stage 3 who were scheduled for either mastectomy or lumpectomy were included in the study. 
Annals of International Medical and Dental Research

E-ISSN: 2395-2822 | P-ISSN: 2395-2814

Vol-8, Issue-2 | March-April 2022

DOI: 10.53339/aimdr.2022.8.2.31

Page no- 245-251 | Section- Research Article (General Surgery)

\section{Inclusion Criteria}

Women diagnosed with carcinoma breast aged between 18 to 80 years.

\section{Exclusion Criteria}

Prior concurrent systemic infection like infection of urinary tract, infection of Lower respiratory tract, infection of gastrointestinal system, pelvic inflammatory disease, local wound infection.

\section{Methodology}

All data were collected from the hospital record room after taking approval from proper authorized channel. Baseline data was collected including patients age, clinically stage of breast cancer, histological stage of breast cancer.

Patient were analysed in two groups based on whether or not patient developed surgical site infection.

Group A- Patient who developed SSI

Group B- Patient who don't develop SSI

All the predisposing factors including BMI, addiction, co-morbidities, preoperative neoadjuvant therapy were recorded. Preoperative and post-operative total lymphocyte count was recorded. Post operatively, patient data were analysed for any surgical site infection, wound dehiscence, day of fever, culture sensitivity report and day of discharge from hospital.

After collection of all the above data, the considered factors were analyzed to recognise factors for development of infection post breast cancer surgery.

\section{RESULTS}

50 pateints of breast cancer were analyzed, selected on basis of mentioned criteria.

Out of total 50 patients, 18 patients under went lumpectomy while 32 patients underwent mastectomy. Histopathological examination of all these patients were done, 35 patients were found to be of invasive ductal carcinoma, 5 patients were of Ductal carcinoma in situ, 8 were of adenocarcinoma, 2 were of invasive lobular carcinoma.

Study patients were taken from 18 to 80 years of age of which maximum patients were of age more than 50 years.

Out of total 50 patients, 10 patients developed Surgical site infection post surgery which were grouped as GROUP A and 40 patients who don't developed SSI were grouped as GROUP B.

In Group A, out of 10 patients, 8 patients were aged more than 50 years and 2 were of less than 50 years of age. Out of 10 infected patients, 7 were having BMI more than $30 \mathrm{~kg} / \mathrm{m}^{2}$ and 3 were having BMI in normal range. 6 out of 10 patients were chronic smoker and 9 patients were having type $2 \mathrm{DM}$ and 2 were having history of Hypertension. In routine investigation, 6 out of 10 infected patients were having TLC more than 11,000. 3 out of 10 patients received Neo-adjuvant chemotherapy.

In Group B patients, out of 40 patients, 30 patients were aged more than 50 years and 10 patients age less than 50 years. 9 out of 40 patients have BMI more than $30 \mathrm{~kg} / \mathrm{m}^{2}, 10$ patients are chronic smoker, 6 patients have 
Annals of International Medical and Dental Research E-ISSN: 2395-2822 | P-ISSN: 2395-2814

Vol-8, Issue-2 | March-April 2022

DOI: 10.53339/aimdr.2022.8.2.31

Page no- 245-251 | Section- Research Article (General Surgery)

history of type $2 \mathrm{DM}$ and 12 patients were having history of Hypertension while only 2 patients have TLC count more than 11,000.

In the non-infected group, 10 out of 40 patients received Neo-adjuvant chemotherapy.

In Group A patients, 9 out of 10 patients operative time was more than 90 minutes from the incision, while in group B 9 out of 40 patients have operative time of more than 90 minutes.

In group A patients, Hospital stay was increased (approx. 10-12 day) while in group B hospital stay was around approx 2-4 days.

Table 1: Comparison of Two Groups (SSI \& NON-SSI)

\begin{tabular}{|c|c|c|c|}
\hline & & SSI & NON-SSI \\
\hline \multirow[t]{2}{*}{ AGE } & $>50 \mathrm{YRS}$ & $8(80 \%)$ & $30(75 \%)$ \\
\hline & $<50 \mathrm{YRS}$ & $2(20 \%)$ & $10(25 \%)$ \\
\hline \multirow[t]{2}{*}{ BMI } & $>30 \mathrm{~kg} / \mathrm{m}^{2}$ & $7(70 \%)$ & $8(20 \%)$ \\
\hline & $<30 \mathrm{~kg} / \mathrm{m}^{2}$ & $3(30 \%)$ & $32(80 \%)$ \\
\hline \multirow[t]{2}{*}{ Smoking } & Present & $6(60 \%)$ & $10(25 \%)$ \\
\hline & Absent & $4(40 \%)$ & $30(75 \%)$ \\
\hline \multirow[t]{4}{*}{ Co Morbidity } & \multirow{2}{*}{$\begin{array}{cc}\text { Hypertension } & \begin{array}{c}\text { Present } \\
\text { Absent }\end{array} \\
\end{array}$} & $2(20 \%)$ & $12(30 \%)$ \\
\hline & & $8(80 \%)$ & $28(70 \%)$ \\
\hline & \multirow[t]{2}{*}{ Diabetes Mellitus } & $9(90 \%)$ & $6(15 \%)$ \\
\hline & & $1(10 \%)$ & $34(85 \%)$ \\
\hline TLC & $>11,000 / \mathrm{mm}^{3}$ & $6(60 \%)$ & $2(5 \%)$ \\
\hline \multirow{2}{*}{$\begin{array}{l}\text { Preop neoadjuvant } \\
\text { chemotherapy }\end{array}$} & Given & $3(30 \%)$ & $10(25 \%)$ \\
\hline & Not Given & $7(70 \%)$ & $30(75 \%)$ \\
\hline
\end{tabular}

Table 2: Surgical Procedure

\begin{tabular}{|l|l|l|l|}
\hline \multicolumn{2}{|l|}{} & SSI & NON-SSI \\
\hline Operative Time & $>90$ Mins & $9(90 \%)$ & $9(22.5 \%)$ \\
\hline \multirow{2}{*}{ Operative Procedure } & Lumpectomy & $3(30 \%)$ & $15(37.5 \%)$ \\
\cline { 2 - 4 } & Mastectomy & $7(70 \%)$ & $25(62.5 \%)$ \\
\hline Length of Hospital Stay & \multicolumn{2}{|l}{} \\
\hline \multirow{2}{*}{ Length of Hospital Stay } & $>5$ Days & $10(100 \%)$ & $30(75 \%)$ \\
\cline { 2 - 4 } & <5 Days & $0(0 \%)$ & $10(25 \%)$ \\
\hline
\end{tabular}

Table 3: Microorganisms causing Surgical Site Infection

\begin{tabular}{|l|l|}
\hline Cultured Organism & Number of Cases \\
\hline P. aeruginosa & 5 \\
\hline Staph aureus & 3 \\
\hline MRSA & 2 \\
\hline
\end{tabular}


Annals of International Medical and Dental Research

E-ISSN: 2395-2822 | P-ISSN: 2395-2814

Vol-8, Issue-2 | March-April 2022

DOI: 10.53339/aimdr.2022.8.2.31

Page no- 245-251 | Section- Research Article (General Surgery)

In culture sensitivity report of the infected patients, pseudomonas aeruginosa growth was present in 5 patients, staphylococcus aureus growth was present in 3 patients and MRSA in 2 patients.

\section{DISCUSSION}

The predictors for an increased incidence of SSI were found to be in patients aged more than 50 years, BMI more than $30 \mathrm{~kg} / \mathrm{m}$, history of smoking, DM, Hypertension. The incidence of SSI in our study was also found to be increased in patients who went through mastectomy $(70 \%)$, preoperative increase in TLC count $(60 \%)$ along with patients who had received Neo-adjuvant chemotherapy $(30 \%)$.

SSI was found to be elevated in patients who had complete breast removal (64\%) vs excision of lump $(36 \%)$. The dissection which is performed in mastectomy results to create a larger dead space along with essentially hypovascular field and tissue flap which lead to increased seroma formation, wound complication and SSI. Removal of complete breast is a lengthier surgery which itself is considered a factor for developing Surgical site infection. [20]

The Associated threatened factors like smoking, DM, increased BMI in developing SSI in breast cancer patients were also proven with consistent data. $[21,22,23,24]$

Other studies have also reported a SSI rate of $20 \%$ in breast cancer surgery patients having association with age (36.1\%), smoking (18.6\%), DM $(20.69 \%)$, BMI $(25.6 \%)$, longer operative time $(9.8 \%)$. .25$]$
With a probable explanation, smoking is linked with vascular impairment which leads to less blood supply to the wound site leading to chance of developing complication. [26]

Similarly, Diabetes is related with wound infection which is consistent with older studies in literature books of surgery.[23]

The above-mentioned findings is secondary to the pathophysiological disturbances i.e., low microcirculation, reduced tissue oxygen levels and disordered wound healing that occur in diabetic patients. $[27,28]$

Additionally, diabetes is associated with obesity, thus making a symbiotic relationship for developing SSI.

SSI due to obesity is due to changes in body physiological system, mechanical weakness due to imbalance between larger area of space and rate of collagen production primarily to Dys-functional myofibroblast and maturation rate of collagen. $29,30,31]$

Additionally, heavy sub-cutaneous fatty tissue results to affect the nearby perforators in the reconstruction area where it led to reduced blood supply to the skin flap, thus creation of a hypoxic surrounding thus causing higher chance of seroma collection and infection. $[32,33]$

There is another interesting hypothesis which would explain the increase in rate of SSI in cases of carcinoma breast as compared to other clean surgeries i.e. the manipulation of breast done numerous times before the index operation. Also, in the process of diagnosis core needle biopsy is done which also manipulates with the breast morphology and architecture. All the above factors are 
Annals of International Medical and Dental Research

E-ISSN: 2395-2822 | P-ISSN: 2395-2814

Vol-8, Issue-2 | March-April 2022

DOI: 10.53339/aimdr.2022.8.2.31

Page no- 245-251 | Section- Research Article (General Surgery)

predisposing the environment to elevate the chance of SSI and to avoid the development of SSI post-operative; further investigation should be done along with administration of preprocedural antibiotic to decrease the risk of SSI.

Overall, my study has concluded mastectomy have higher overall increase in incidence of SSI in the patient related with higher age, increased BMI, Addiction, co-morbidity and increase in operative time.

Similarly, patient who received neoadjuvant therapy has shown near significant increase in incidence of SSI post-operative.

\section{REFERENCES}

1. Yeole BB, Kurkure AP, Sunny L. Cancer survival in Mumbai (Bombay), India, 1992-1999. IARC Sci Publ. 2011;(162):133-42.

2. Seltzer MH. Partial mastectomy and limited axillary dissection performed as a same day surgical procedure in the treatment of breast cancer. Int Surg. 1995;80(1):7981.

3. Vazquez-Aragon P, Lizan-Garcia M, Cascales-Sanchez P, Villar-Canovas MT, Garcia-Olmo D. Nosocomial infection and related risk factors in a general surgery service: a prospective study. J Infect. 2003;46(1):17-22. doi: 10.1053/jinf.2002.1073.

4. El-Tamer MB, Ward BM, Schifftner T, Neumayer L, Khuri S, Henderson W. Morbidity and mortality following breast cancer surgery in women: national benchmarks for standards of care. Ann Surg. 2007;245(5):665-71. doi: 10.1097/01.sla.0000245833.48399.9a.

5. Olsen MA, Nickel KB, Fox IK, Margenthaler JA, Ball KE, Mines D, et al. Incidence of Surgical Site Infection Following Mastectomy With and Without Immediate Reconstruction Using Private Insurer Claims Data. Infect Control Hosp Epidemiol. 2015;36(8):907-14. doi: 10.1017/ice.2015.108.

6. Degnim AC, Throckmorton AD, Boostrom SY, et al. Surgical site infection after breast surgery: impact of

\section{CONCLUSIONS}

In our study we found that in patients of Age more than 50years or who underwent Mastectomy or having associated co-morbidity with co-relation to Smoking \& BMI more than 30 with Increased TLC count or who have received Neo-adjuvant chemotherapy are linked with increased chance of SSI following surgery for carcinoma of breast which has led to increased hospital stay. There are many other studies who also concluded the relation of above factors with development of SSI post breast surgery, however more research will be appreciated to make clear the effect of older manipulation and radiation session in developing SSI.

2010 CDC reporting guidelines. Ann Surg Oncol. 2012;19(13):4099-4103. doi:10.1245/s10434-012-2448-6

7. Gulluoglu BM, Guler SA, Ugurlu MU, Culha G. Efficacy of prophylactic antibiotic administration for breast cancer surgery in overweight or obese patients: a randomized controlled trial. Ann Surg. 2013;257(1):3743. doi: 10.1097/SLA.0b013e31826d832d.

8. Williams N, Sweetland H, Goyal S, Ivins N, Leaper DJ. Randomized trial of antimicrobial-coated sutures to prevent surgical site infection after breast cancer surgery. Surg Infect (Larchmt). 2011;12(6):469-74. doi: 10.1089/sur.2011.045.

9. Reilly J, Twaddle S, McIntosh J, Kean L. An economic analysis of surgical wound infection. J Hosp Infect. 2001;49(4):245-9. doi: 10.1053/jhin.2001.1086.

10. Letrilliart L, Guiguet $M$, Hanslik T, Flahault A. Postdischarge nosocomial infections in primary care. Infect Control Hosp Epidemiol. 2001;22(8):493-8. doi: 10.1086/501939.

11. Vilar-Compte D, Mohar A, Sandoval S, de la Rosa M, Gordillo P, Volkow P. Surgical site infections at the National Cancer Institute in Mexico: a case-control study. Am J Infect Control. 2000;28(1):14-20. doi: 10.1016/s0196-6553(00)90006-3.

12. Coello R, Charlett A, Wilson J, Ward V, Pearson A, Borriello P. Adverse impact of surgical site infections in English hospitals. J Hosp Infect. 2005;60(2):93-103. doi: 10.1016/j.jhin.2004.10.019. 
Annals of International Medical and Dental Research E-ISSN: 2395-2822 | P-ISSN: 2395-2814

Vol-8, Issue-2 | March-April 2022

DOI: 10.53339/aimdr.2022.8.2.31

Page no- 245-251 | Section- Research Article (General Surgery)

13. Olsen MA, Chu-Ongsakul S, Brandt KE, Dietz JR, Mayfield J, Fraser VJ. Hospital-associated costs due to surgical site infection after breast surgery. Arch Surg. 2008;143(1):53-60; discussion $61 . \quad$ doi: 10.1001/archsurg.2007.11.

14. Avritscher EB, Cooksley CD, Rolston KV, Swint JM, Delclos GL, Franzini L, et al. Serious postoperative infections following resection of common solid tumors: outcomes, costs, and impact of hospital surgical volume. Support Care Cancer. 2014;22(2):527-35. doi: 10.1007/s00520-013-2006-1.

15. Bertin ML, Crowe J, Gordon SM. Determinants of surgical site infection after breast surgery. Am J Infect Control. 1998;26(1):61-5. doi: 10.1016/s01966553(98)70062-8.

16. Nieto A, Lozano M, Moro MT, Keller J, Carralafuente C. Determinants of wound infections after surgery for breast cancer. Zentralbl Gynakol. 2002;124(8-9):429-33. doi: $10.1055 /$ s-2002-38129.

17. Wagman LD, Tegtmeier B, Beatty JD, Kloth DD, Kokal WA, Riihimaki DU, Terz JJ. A prospective, randomized double-blind study of the use of antibiotics at the time of mastectomy. Surg Gynecol Obstet. 1990;170(1):12-6.

18. Rotstein C, Ferguson R, Cummings KM, Piedmonte MR, Lucey J, Banish A. Determinants of clean surgical wound infections for breast procedures at an oncology center. Infect Control Hosp Epidemiol. 1992;13(4):20714. doi: $10.1086 / 646511$.

19. Lipshy KA, Neifeld JP, Boyle RM, Frable WJ, Ronan S, Lotfi $P$, et al. Complications of mastectomy and their relationship to biopsy technique. Ann Surg Oncol. 1996;3(3):290-4. doi: 10.1007/BF02306285.

20. de Blacam C, Ogunleye AA, Momoh AO, Colakoglu S, Tobias AM, Sharma R, et al. High body mass index and smoking predict morbidity in breast cancer surgery: a multivariate analysis of 26,988 patients from the national surgical quality improvement program database. Ann Surg. 2012;255(3):551-5. doi: 10.1097/SLA.0b013e318246c294.

21. Chow I, Hanwright PJ, Hansen NM, Leilabadi SN, Kim JY. Predictors of 30-day readmission after mastectomy: A multi-institutional analysis of 21,271 patients. Breast Dis. 2015;35(4):221-31. doi: 10.3233/BD-150412.

22. Olsen MA, Lefta M, Dietz JR, Brandt KE, Aft R, Matthews $\mathrm{R}$, et al. Risk factors for surgical site infection after major breast operation. J Am Coll Surg. 2008;207(3):326-35. 10.1016/j.jamcollsurg.2008.04.021.

23. Ata A, Lee J, Bestle SL, Desemone J, Stain SC. Postoperative hyperglycemia and surgical site infection in general surgery patients. Arch Surg. 2010;145(9):85864. doi: 10.1001/archsurg.2010.179.

24. Sørensen LT, Hørby J, Friis E, Pilsgaard B, Jørgensen T. Smoking as a risk factor for wound healing and infection in breast cancer surgery. Eur J Surg Oncol. 2002;28(8):815-20. doi: 10.1053/ejso.2002.1308.

25. Ashraf M, Biswas J, Gupta S, Alam N. Determinants of wound infections for breast procedures: assessment of the risk of wound infection posed by an invasive procedure for subsequent operation. Int J Surg. 2009;7(6):543-6. doi: 10.1016/j.ijsu.2009.08.012.

26. Jain RK. Clearing the smoke on nicotine and angiogenesis. Nat Med. 2001;7(7):775-7. doi: $10.1038 / 89889$.

27. Cicco G, Giorgino F, Cicco S. Wound healing in diabetes: hemorheological and microcirculatory aspects. Adv Exp Med Biol. 2011;701:263-9. doi: 10.1007/978-14419-7756-4_35.

28. Sharp A, Clark J. Diabetes and its effects on wound healing. Nurs Stand. 2011;25(45):41-7. doi: 10.7748/ns2011.07.25.45.41.c8626.

29. Enser M, Avery NC. Mechanical and chemical properties of the skin and its collagen from lean and obese-hyperglycaemic (ob/ob) mice. Diabetologia. 1984;27(1):44-9. doi: 10.1007/BF00253500.

30. Goodson WH 3rd, Hunt TK. Wound collagen accumulation in obese hyperglycemic mice. Diabetes. 1986;35(4):491-5. doi: 10.2337/diab.35.4.491.

31. Xing L, Culbertson EJ, Wen Y, Robson MC, Franz MG. Impaired laparotomy wound healing in obese rats. Obes Surg. 2011;21(12):1937-46. doi: 10.1007/s11695-011-03772.

32. Scheflan M, Kalisman M. Complications of breast reconstruction. Clin Plast Surg. 1984;11(2):343-50.

33. Wilson JA, Clark JJ. Obesity: impediment to wound healing. Crit Care Nurs Q. 2003;26(2):119-32. doi: 10.1097/00002727-200304000-00006.

Source of Support: Nil, Conflict of Interest: None declared 